\title{
Investigating Alternative Acidic Proteases for H/D Exchange Coupled to Mass Spectrometry: Plasmepsin 2 but not Plasmepsin 4 Is Active Under Quenching Conditions
}

\author{
Julien Marcoux, a,b Eric Thierry, ${ }^{\mathrm{a}}$ Corinne Vivès, ${ }^{\mathrm{b}}$ Luca Signor, ${ }^{\mathrm{a}}$ \\ Franck Fieschi, ${ }^{b}$ and Eric Forest ${ }^{a}$ \\ a Laboratoire de Spectrométrie de Masse des Protéines, Institut de Biologie Structurale, Grenoble, France \\ ${ }^{b}$ Laboratoire des Protéines Membranaires, Université Joseph Fourier, Institut de Biologie Structurale (IBS), \\ Grenoble, France
}

Structural studies of proteins by hydrogen/deuterium exchange coupled to mass spectrometry (DXMS) require the use of proteases working at acidic $\mathrm{pH}$ and low temperatures. The spatial resolution of this technique can be improved by combining several acidic proteases, each generating a set of different peptides. Three commercial aspartic proteases are used, namely, pepsin, and proteases XIII and XVIII. However, given their low purity, high enzyme/protein ratios have to be used with proteases XIII and XVIII. In the present work, we investigate the activity of two alternative acidic proteases from Plasmodium falciparum under different $\mathrm{pH}$ and temperature conditions. Peptide mapping of four different proteins after digestion with pepsin, plasmepsin 2 (PSM2), and plasmepsin 4 (PSM4) were compared. PSM4 is inactive at $\mathrm{pH} 2.2$ and $0{ }^{\circ} \mathrm{C}$, making it unusable for DXMS studies. However, PSM2 showed low but reproducible activity under DXMS conditions. It displayed no substrate specificity and, like pepsin, no strict sequence specificity. Altogether, these results show that PSM2 but not PSM4 is a potential new tool for DXMS studies. (J Am Soc Mass Spectrom 2010, 21, 76-79) (c) 2010 American Society for Mass Spectrometry

$\mathrm{D}$ XMS has recently been widely used to improve the structural knowledge of protein complexes that are too large for NMR [1] or too flexible for crystallographic [2] studies, and to obtain complementary information on ligand binding [3] or protein dynamics [4]. One of the main time-consuming steps of this method is the peptide mapping of the protein of interest, after digestion with a nonspecific protease. Acidic proteases are used since their proteolytic activity is maintained under hydrogen/deuterium exchange mass spectrometry (DXMS) experimental conditions, i.e., between $\mathrm{pH} 2$ and 3 and at $0{ }^{\circ} \mathrm{C}$ where $\mathrm{H} / \mathrm{D}$ back-exchange is minimal [5]. To reduce back-exchange, one must also work with proteases able to digest proteins within a few minutes. Recently, new insights in fragmentation techniques, limiting the intramolecular migration of hydrogens, have allowed reaching singleresidue resolution. However, so far these techniques have been tested only with synthetic peptides or small proteins such as myoglobin [6]. The combined use of alternative acidic proteases with different specificities is

Address reprint requests to Dr. E. Forest, Institut de Biologie Structurale, Laboratoire de Spectrométrie de Masse des Protéines, 41 Avenue des Martyrs, 38027 Grenoble, France. E-mail: eric.forest@ibs.fr another way to improve the method's resolution. Our laboratory has developed the use of commercial-type XIII and XVIII fungal proteases [7, 8] that are now routinely used to improve the resolution of DXMS studies $[9,10]$. However, the presence of impurities requires high enzyme/protein ratios (10.5:1 (wt/wt) for protease type XIII and 17:1 for protease type XVIII) [7]. Recently, we developed recombinant type XVIII protease with higher purity and activity [11].

In the present study, the use of two alternative recombinant aspartic proteases from the parasite Plasmodium falciparum, plasmepsins 2 (EC 3.4.23.39) and 4 (EC 3.4.23.B14), is evaluated with the goal of improving protein mapping and spatial resolution in DXMS experiments. Plasmepsins play an important role in the intra-erythrocytic digestion of hemoglobin responsible for the tropical disease malaria. Structural and enzymatic studies were previously reported $[12,13]$. However, very little is known about their sequence and substrate specificities. This study shows for the first time that PSM2 can be used to digest nonerythrocytic proteins. We obtained peptide maps and were thus able to compare plasmepsin activity under DXMS conditions with other proteolytic results (pepsin), not only on their natural substrate (hemoglobin), but also on myoglobin 
and the PX domain of p47 $7^{\text {phox }}$ (p47 $7^{\text {phox }}-\mathrm{PX}$ ), a cytosolic factor of the neutrophil NADPH oxydase [4].

\section{Experimental}

\section{Materials}

All proteins were from Sigma-Aldrich (St. Louis, MO, USA). The reversed-phase C18 column Jupiter $(50 \times$ $1.00 \mathrm{~mm} ; 5 \mu \mathrm{m}, 300 \AA$ ) was from Phenomenex (Torrance, CA, USA) and the protein MacroTrap C8 was from Michrom Bioresources (Auburn, CA, USA).

\section{Protein Expression and Purification}

PSM2 (residues 78-453) and PSM4 (residues 74-448) clones were the kind gifts of Professor Ben M. Dunn (University of Florida). Plasmepsin expression and purification were carried out according to Westling et al. [14]. p47 $7^{\text {phox }}$-PX was expressed in E. coli BL21(DE3) and purified according to the protocol used for the entire p47 $7^{\text {phox }}$ described in Durand et al. [15].

\section{Protein Digestion and Protease Cleavage}

A total of 338 pmol of protein were digested for $2 \mathrm{~min}$ at a 1:1 enzyme/protein ratio $(\mathrm{wt} / \mathrm{wt})$. Digestions were carried out in $10 \mathrm{mM}$ glycine $\mathrm{pH} 2.2$ or in $50 \mathrm{mM}$ citrate $\mathrm{pH}$ 4.5. PSM4 was activated for $40 \mathrm{~min}$ in $50 \mathrm{mM}$ citrate $\mathrm{pH} 4.5$.

\section{LC-MS and LC-MS/MS}

Before MS analysis, peptides were desalted for $1 \mathrm{~min}$ on a MacroTrap column at a $400-\mu \mathrm{L} / \mathrm{min}$ flow rate with a $0.03 \%$ TFA water solution. Peptides were then eluted with an 8-min step gradient (0-10-15-20-25-30-35 and $45 \%$ of $95 \%$ acetonitrile, $0.03 \%$ TFA) for peptide mapping, which was performed on a quadrupole ion trap mass spectrometer (ESQUIRE 3000+; Bruker Daltonics, Billerica, MA, USA) equipped with an electrospray ionization source (ESI). For MS/MS experiments, the three most intense ions were fragmented and then excluded after two spectra had been obtained. Data processing was done using Bruker Data Analysis 3.0 software and Mascot server. MS/MS spectra were checked manually and confirmed by accurate mass measurement on an ESI-time-of-flight (TOF) mass spectrometer (6210; Agilent Technologies, Santa Clara, CA, USA). The Agilent software MassHunter and MagTran were used for data processing. Peptide maps were made with scripts available at http://ms.biomed.cas. cz/MSTools/.

\section{Results and Discussion}

PSM2 and PSM4 are generally studied under physiological conditions $\left(37^{\circ} \mathrm{C}, \mathrm{pH} 4.5\right)$. Maturation of the 43-kDa PSM2 precursor into the 38-kDa activated form was achieved most often at $37^{\circ} \mathrm{C}$ or room temperature for $40 \mathrm{~min}$ to $2 \mathrm{~h}$ and $\mathrm{pH} 4.5$ to $\mathrm{pH} 5$ [16-18]. Maturation of PSM4 was shown to be efficient after $5 \mathrm{~min}$ at $\mathrm{pH} 4.5$ and $37^{\circ} \mathrm{C}$ [19]. We determined the optimal time for plasmepsin maturation by following their auto-cleavage on ESI-TOF MS (Figure S1 available as supplementary material, which can be found in the electronic version of this article). PSM2 auto-cleavage after F112 was complete after $20 \mathrm{~min}$ in $10 \mathrm{mM}$ citrate $\mathrm{pH} 4.5$ (Figure S1 available as supplementary material, which can be found in the electronic version of this article). After $10 \mathrm{~min}$ at room temperature in $10 \mathrm{mM}$ citrate $\mathrm{pH}$ 4.5, PSM4 was partly cleaved after Phe109 (38,218 Da), Phe110 (38,071 Da), or Phe81 (41,508 Da); however, cleavage was not complete, even after $7 \mathrm{~h}$ (data not shown). We finally used a 40-min maturation time for further experiments with PSM4. PSM2 and PSM4 activity on bovine hemoglobin was then tested before and after maturation at $\mathrm{pH} 4.5$, at two different acidic $\mathrm{pHs}$ and two different temperatures (Figure 1a). Table S1 (available as supplementary material, which can be found in the electronic version of this article) lists the identified cleavage sites. Reproducibility of the digestion was confirmed by triplicate ESI-TOF MS accurate mass measurement. PSM2 was active in all tested conditions, but at $\mathrm{pH} 4.5$, the number of cleavage sites was lower at $0{ }^{\circ} \mathrm{C}$ than at room temperature (13 versus 19 cleavage sites for the nonmature form). PSM2 produced more cleavage sites at $\mathrm{pH} 4.5$ than at $\mathrm{pH} 2.2$ (13 versus 10 cleavage sites, at $0{ }^{\circ} \mathrm{C}$ for the nonmature form). Interestingly, PSM2 was less active after maturation (19 versus 12 cleavage sites at room temperature). At $\mathrm{pH}$ 2.2, PSM2 activity was surprisingly observed only without maturation (intact plasmepsin was identified at the end of the LC-MS run). Contrary to PSM2, PSM4 was more active after maturation. It was able to digest bovine hemoglobin in different $\mathrm{pH}$ and temperature conditions, but its activity was considerably lowered at $\mathrm{pH} 2.2$ (five cleavage sites at room temperature and only one at $0{ }^{\circ} \mathrm{C}$ ), making it unusable for DXMS. Proteolytic activity was also tested on human hemoglobin with nonmature PSM2 at $\mathrm{pH} 2.2$ and $0{ }^{\circ} \mathrm{C}$. More than $70 \%$ of sequence coverage was obtained with 16 identified cleavage sites (Figure 1b). Similar results were obtained with mature PSM4 but at $\mathrm{pH} 4.5$ and room temperature (11 identified cleavage sites). In conclusion, these first experiments using hemoglobin as substrate showed PSM2 as a candidate for DXMS experiments since it was active at $\mathrm{pH} 2.2$ and $0{ }^{\circ} \mathrm{C}$ for 2 min of digestion time, at an 1:1 enzyme/protein (wt/ wt) ratio, in contrast with PSM4.

To investigate the substrate specificity of PSM2 and PSM4, we tested their activity on nonerythrocytic proteins. Horse myoglobin was chosen because of its structural similarity with hemoglobin and $\mathrm{p} 47^{\text {phox }}$-PX because of its nonrelated structure. Horse myoglobin and $47^{\text {phox }}$-PX were digested by pepsin and PSM2 (Figure 2) but not by PSM4, even at $\mathrm{pH} 4.5$ and room 


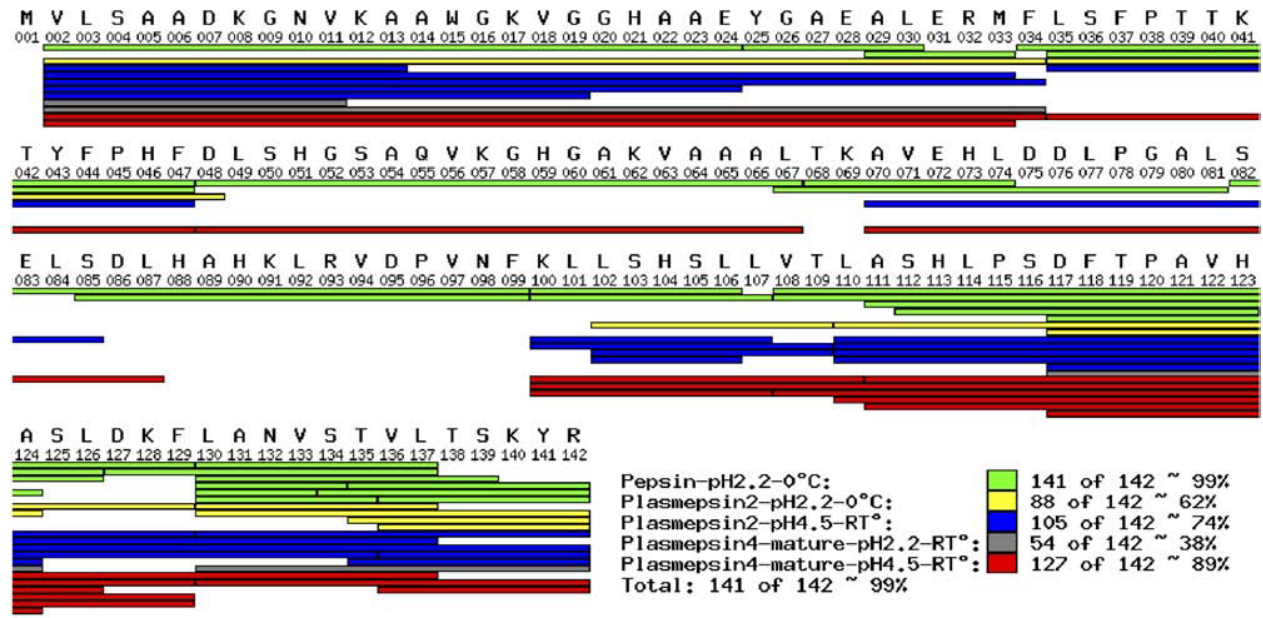

(a)

MVL S P A D K T N V K A A W G K V G A H A G E Y G A E A L E R M F L S F P T T K 0020030040050060070080090100110120130140150160170180190200210220230240250260270280290300310320033034035036037038039040041

T Y F P H F D L S H G S A Q V K G H G K K V A D A L T N A V A H V D D M P N A L S

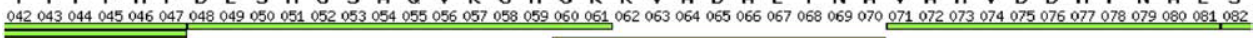
A L S D L H A H K L R V D P V N F K L L S H C L L V T L A A H L P A E F T P A V H 083084085086087088089090091092093094095096097098099100101102103104105106107108109110111112113114115116117118119120121122123

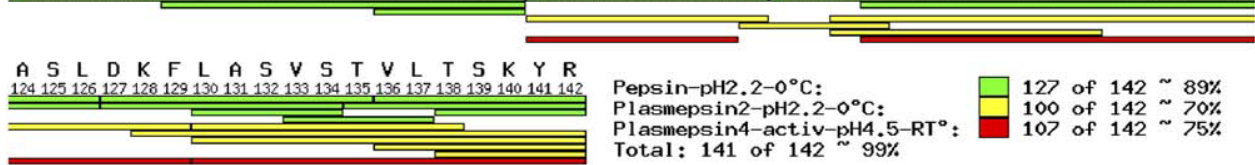

(b)

Figure 1. Peptide map of bovine (a) and human (b) hemoglobin $\alpha$ subunit after digestion with pepsin, non-mature PSM2, and mature PSM4. Different $\mathrm{pH}$ and temperature conditions and percentages of coverage are indicated in the insets.

temperature. These results confirm the broad substrate specificity of PSM2, which is able to digest proteins not only from erythrocyte cytoskeleton [18], but also from muscle cells and neutrophils. On the contrary, PSM4 seems to be only able to digest its physiologic substrate (human hemoglobin) or species homologues.

A broad-spectrum substrate does not exclude any sequence motif recognition or at least any preference for certain amino acids. Acidic proteases used for H/D exchange such as pepsin and proteases type XIII and XVIII are not really specific even though pepsin was described to cleave preferentially on the C-terminal end of Met, Phe, and Leu [20]. Protease type XIII was recently shown to favor cleavage after basic amino acids [10]. Specific acidic proteases would considerably reduce the experimental and data analysis time by avoid-

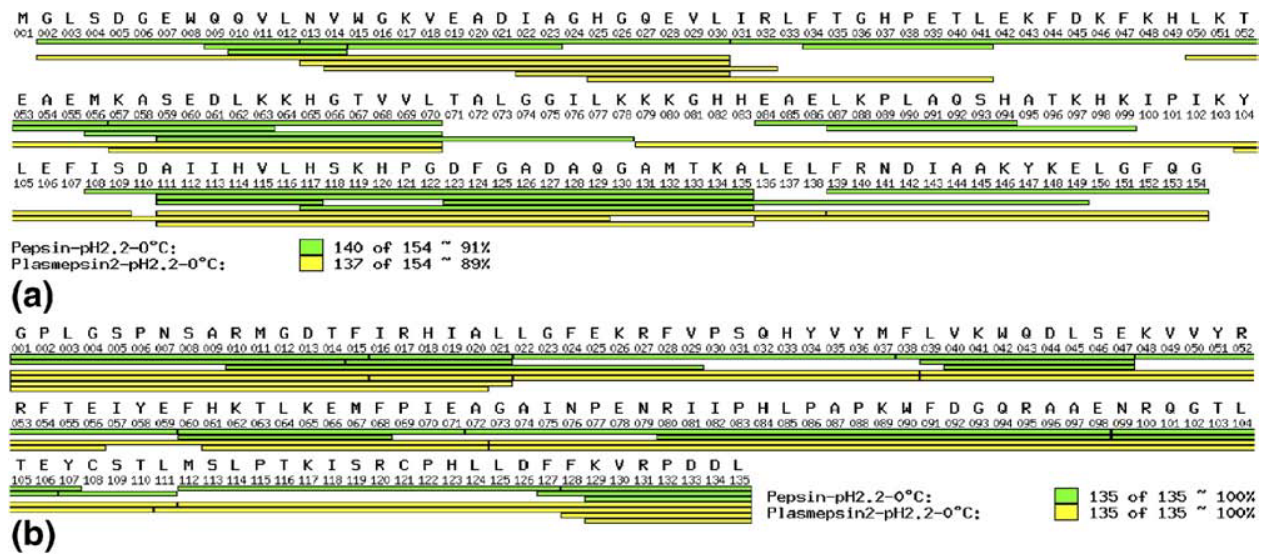

Figure 2. Peptide map of (a) horse myoglobin and (b) p47phox-PX after digestion with pepsin and PSM2 at $\mathrm{pH} 2.2$ and $0{ }^{\circ} \mathrm{C}$. Percentages of coverage are indicated in the insets. 
ing the MS/MS peptide identification step. However, low specificity is generally considered to be an advantage for DXMS experiments because it leads to a large number of peptides [20], which increases the spatial resolution of the analysis. We identified here different cleavage sites on various proteins to evaluate plasmepsin specificity. Digestion of bovine hemoglobin $\alpha$ subunit, at $\mathrm{pH} 2.2$ and $0{ }^{\circ} \mathrm{C}$, with either pepsin or PSM2, generated peptides by cleavage after eight different types of residues. This large number of recognized residues seems to indicate low sequence specificity. The proportions of cleavage sites that are obtained with PSM2 but not with pepsin were $30 \%, 50 \%, 47 \%$ and $45 \%$ for bovine and human hemoglobin, myoglobin, and p47 ${ }^{\text {phox }}$-PX, respectively (Figures 1 and 2), showing the complementarities of both enzymes. Finally, the average size of peptides generated by digestion of the four proteins under DXMS conditions was 12 versus 15.5 for pepsin and PSM2, respectively.

\section{Conclusions}

Recombinant PSM2 and PSM4 from Plasmodium falciparum were studied for the first time as new tools for structural biology studies. PSM2 activity does not seem to be enhanced upon maturation. However, it was still active at $\mathrm{pH} 2.2$ and $0{ }^{\circ} \mathrm{C}$, contrary to PSM4, which therefore cannot be used for DXMS experiments. Moreover, in these conditions, PSM2 was able to digest not only bovine and human hemoglobin (its physiologic substrate), but also horse myoglobin and $\mathrm{p} 47^{\text {phox }}$-PX, chosen as representatives of nonerythrocytic and structurally different proteins. Despite close sequence specificity of PSM2 with pepsin, both proteases were able to generate unique cleavage sites, thus showing their complementarity. The ability of PM2 to work under quenching conditions and its low substrate and sequence specificities positions it as a potential novel protease to increase DXMS resolution, even though it was less active than pepsin under quenching conditions. Further studies need to be conducted in this field to develop an increasing number of proteolytic tools for DXMS. Comparison of plasmepsin activity and specificity from different Plasmodium species could be interesting, since some of them have been described as more efficient in acidic conditions [19].

\section{Acknowledgments}

The authors are grateful to Professor Ben M. Dunn and Melissa Marzahn (University of Florida) for their kind gift of Plasmodium falciparum clones expressing PSM2 and PSM4. The authors also thank Daniel Kavan (Institute of Microbiology, Prague) for the development of scripts facilitating data processing and interpretation.

\section{Appendix A. Supplementary Material}

Supplementary material associated with this article may be found in the online version at doi:10.1016/ j.jasms.2009.09.005.

\section{References}

1. Suchanova, B.; Tuma, R. Folding and Assembly of Large Macromolecular Complexes Monitored by Hydrogen-Deuterium Exchange and Mass Spectrometry. Microbiol. Cell Fact. 2008, 7:12.

2. Li, J.; Lim, M. S.; Li, S.; Brock, M.; Pique, M. E.; Woods, V. L. Jr.; Craig, L. Vibrio Cholerae Toxin-Coregulated Pilus Structure Analyzed by Hydrogen/Deuterium Exchange Mass Spectrometry. Structure 2008, 16, 137-148.

3. Brier, S.; Lemaire, D.; Debonis, S.; Forest, E.; Kozielski, F. Identification of the Protein Binding Region of S-Trityl-L-Cysteine, a New Potent Inhibitor of the Mitotic Kinesin Eg5. Biochemistry 2004, 43, 13072-13082.

4. Marcoux, J.; Man, P.; Castellan, M.; Vives, C.; Forest, E.; Fieschi, F. Conformational Changes in p47(phox) Upon Activation Highlighted by Mass Spectrometry Coupled to Hydrogen/Deuterium Exchange and Limited Proteolysis. FEBS Lett. 2009, 583, 835-840.

5. Bai, Y.; Milne, J. S.; Mayne, L.; Englander, S. W. Primary Structure Effects on Peptide Group Hydrogen Exchange. Proteins 1993, 17, 75-86.

6. Pan, J.; Han, J.; Borchers, C. H.; Konermann, L. Hydrogen/Deuterium Exchange Mass Spectrometry with Top-Down Electron Capture Dissociation for Characterizing Structural Transitions of a $17 \mathrm{kDa}$ Protein. J. Am. Chem. Soc. 2009, 131, 12801-12808.

7. Cravello, L.; Lascoux, D.; Forest, E. Use of Different Proteases Working in Acidic Conditions to Improve Sequence Coverage and Resolution in Hydrogen/Deuterium Exchange of Large Proteins. Rapid Commun. Mass Spectrom. 2003, 17, 2387-2393.

8. Man, P.; Montagner, C.; Vernier, G.; Dublet, B.; Chenal, A.; Forest, E.; Forge, V. Defining the Interacting Regions Between Apomyoglobin and Lipid Membrane by Hydrogen/Deuterium Exchange Coupled to Mass Spectrometry. J. Mol. Biol. 2007, 368, 464-472.

9. Alverdi, V.; Mazon, H.; Versluis, C.; Hemrika, W.; Esposito, G.; van den Heuvel, R.; Scholten, A.; Heck, A. J. cGMP-Binding Prepares PKG for Substrate Binding by Disclosing the C-Terminal Domain. J. Mol. Biol. 2008, 375, 1380-1393

10. Zhang, H. M.; Kazazic, S.; Schaub, T. M.; Tipton, J. D.; Emmett, M. R.; Marshall, A. G. Enhanced Digestion Efficiency, Peptide Ionization efficiency, and Sequence Resolution for Protein Hydrogen/Deuterium Exchange Monitored by Fourier Transform Ion Cyclotron Resonance Mass Spectrometry. Anal Chem. 2008, 80, 9034-9041.

11. Rey, M.; Man, P.; Brandolin, G.; Forest, E.; Pelosi, L. Recombinant Immobilized Rhizopus Pepsin as a New Tool for Protein Digestion in H/D Exchange Mass Spectrometry. Rapid Commun. Mass Spectrom. 2009, 23, 3431-3438.

12. Madabushi, A.; Chakraborty, S.; Fisher, S. Z.; Clemente, J. C.; Yowell, C.; Agbandje-McKenna, M.; Dame, J. B.; Dunn, B. M.; McKenna, R. Crystallization and Preliminary X-ray Analysis of the Aspartic Protease Plasmepsin 4 from the Malarial Parasite Plasmodium malariae. Acta Crystallogr. F Struct Biol. Cryst. Commun. 2005, 61, 228-231.

13. Silva, A. M.; Lee, A. Y.; Gulnik, S. V.; Maier, P.; Collins, J.; Bhat, T. N.; Collins, P. J.; Cachau, R. E.; Luker, K. E.; Gluzman, I. Y.; Francis, S. E.; Oksman, A.; Goldberg, D. E.; Erickson, J. W. Structure and Inhibition of Plasmepsin II, a Hemoglobin-Degrading Enzyme from Plasmodium falciparum. Proc. Natl. Acad Sci. U.S.A. 1996, 93, 10034-10039.

14. Westling, J.; Cipullo, P.; Hung, S. H.; Saft, H.; Dame, J. B.; Dunn, B. M. Active Site Specificity of Plasmepsin II. Protein Sci. 1999, 8, 2001-2009.

15. Durand, D.; Cannella, D.; Dubosclard, V.; Pebay-Peyroula, E.; Vachette, P.; Fieschi, F. Small-Angle X-ray Scattering Reveals an Extended Organization for the Autoinhibitory Resting State of the p47(phox) Modular Protein. Biochemistry 2006, 45, 7185-7193.

16. Hill, J.; Tyas, L.; Phylip, L. H.; Kay, J.; Dunn, B. M.; Berry, C. High Level Expression and Characterization of Plasmepsin II, an Aspartic Proteinase from Plasmodium falciparum. FEBS Lett. 1994, 352, 155-158.

17. Kim, Y. M.; Lee, M. H.;Piao, T. G.; Lee, J. W.; Kim, J. H.; Lee, S. Choi, K. M Jiang, J. H.; Kim, T. U.; Park, H. Prodomain Processing of Recombinant Plasmepsin II and IV, the Aspartic Proteases of Plasmodium falciparum, is auto- and transcatalytic. J. Biochem. 2006, 139, 189-195.

18. Le Bonniec, S.; Deregnaucourt, C.; Redeker, V.; Banerjee, R.; Grellier, P.; Goldberg, D. E.; Schrevel, J. Plasmepsin II, an Acidic Hemoglobinase from the Plasmodium falciparum food vacuole, is active at neutral $\mathrm{pH}$ on the host erythrocyte membrane skeleton. J. Biol. Chem. 1999, 274, 14218-14223

19. Li, T.; Yowell, C. A.; Beyer, B. B.; Hung, S. H.; Westling, J.; Lam, M. T.; Dunn, B. M.; Dame, J. B. Recombinant Expression and Enzymatic Subsite Characterization of Plasmepsin 4 from the four Plasmodium Species Infecting Man. Mol. Biochem. Parasitol. 2004, 135, 101-109.

20. Smith, D. L.; Deng, Y.; Zhang, Z. Probing the Noncovalent Structure of Proteins by Amide Hydrogen Exchange and Mass Spectrometry. J. Mass Spectrom. 1997, 32, 135-146. 